\title{
Referral and treatment pathways for pseudomyxoma peritonei of appendiceal origin within a national treatment programme
}

DOI:

10.1111/codi. 14310

\section{Document Version}

Accepted author manuscript

Link to publication record in Manchester Research Explorer

Citation for published version (APA):

Fish, R., Renehan, A. G., Punnett, G., Aziz, O., Fulford, P., Selvasekar, C., Wilson, M., Halstead, R., \& O'Dwyer, S. T. (2018). Referral and treatment pathways for pseudomyxoma peritonei of appendiceal origin within a national treatment programme. Colorectal disease : the official journal of the Association of Coloproctology of Great Britain and Ireland, 20(10), 888-896. https://doi.org/10.1111/codi.14310

\section{Published in:}

Colorectal disease : the official journal of the Association of Coloproctology of Great Britain and Ireland

\section{Citing this paper}

Please note that where the full-text provided on Manchester Research Explorer is the Author Accepted Manuscript or Proof version this may differ from the final Published version. If citing, it is advised that you check and use the publisher's definitive version.

\section{General rights}

Copyright and moral rights for the publications made accessible in the Research Explorer are retained by the authors and/or other copyright owners and it is a condition of accessing publications that users recognise and abide by the legal requirements associated with these rights.

\section{Takedown policy}

If you believe that this document breaches copyright please refer to the University of Manchester's Takedown Procedures [http://man.ac.uk/04Y6Bo] or contact uml.scholarlycommunications@manchester.ac.uk providing relevant details, so we can investigate your claim.

\section{OPEN ACCESS}


MS REBECCA FISH (Orcid ID : 0000-0002-4239-6993)

Article type : Original Article

061-2018.R1

Original Article

\section{Referral and treatment pathways for pseudomyxoma peritonei of appendiceal origin within a national treatment programme}

\footnotetext{
${ }^{1,2}$ Rebecca Fish, ${ }^{1,2,3}$ Andrew G Renehan, ${ }^{1}$ Grant Punnett, ${ }^{1,2}$ Omer Aziz, ${ }^{1}$ Paul Fulford, ${ }^{1}$ Chelliah Selvasekar, ${ }^{1}$ Malcolm Wilson, ${ }^{1}$ Rebecca Halstead, ${ }^{1,2}$ Sarah T. O'Dwyer
}

${ }^{1}$ Colorectal and Peritoneal Oncology Centre, The Christie NHS Foundation Trust, Manchester, United Kingdom

${ }^{2}$ Division of Cancer Sciences, School of Medical Sciences, Faculty of Biology, Medicine and Health, University of Manchester, Manchester Academic Health Science Centre, Manchester, United Kingdom

${ }^{3}$ Manchester Cancer Research Centre, NIHR Manchester Biomedical Research Centre, University of Manchester, Manchester, United Kingdom

\section{SYNOPSIS}

The 13-year experience of pseudomyxoma peritonei at a national specialist centre

\section{KEYWORDS}

Pseudomyxoma peritonei; low grade appendiceal mucinous neoplasm; cytoreduction; heated intraperitoneal chemotherapy

\section{Correspondence to:}

This article has been accepted for publication and undergone full peer review but has not been through the copyediting, typesetting, pagination and proofreading process, which may lead to differences between this version and the Version of Record. Please cite this article as doi: 10.1111/codi.14310

This article is protected by copyright. All rights reserved. 


\author{
Professor Andrew Renehan \\ Colorectal and Peritoneal Oncology Centre, \\ The Christie NHS Foundation Trust, \\ Wilmslow Road \\ Manchester, M20 4BX \\ E-mail: andrew.renehan@ christie.nhs.uk
}

\begin{abstract}
246 words (max: 250); main text: 2583 words (max: 3000); 1 table; 6 figures; 28 references; language: UK English
\end{abstract}

\begin{abstract}
Aim Pseudomyxoma peritonei (PMP) is a rare neoplasm of the appendix, which if untreated disseminates throughout the abdominal cavity and generates considerable morbidity. Since 2002 in the UK, patients with PMP have been managed via two nationally commissioned centres. We evaluated referrals and treatment pathways over time at the Manchester centre.

Method Data from all patients referred with suspected PMP were prospectively collected (2002-2015). Definitive treatment was cytoreductive surgery (CRS) and hyperthermic intraperitoneal chemotherapy (HIPEC). Disease burden was quantified using the Peritoneal Cancer Index (PCI: score 0-39) and complete cytoreduction (CC) defined by scores of 0/1. Novel treatment algorithms were developed for patients with low-grade appendiceal mucinous neoplasm (LAMN) localised to the peri-appendiceal tissue.
\end{abstract}

Results 817 patients with confirmed PMP were referred increasing from 11 in 2002 to 103 in 2015. Disease burden was high with mean $P C I$ of 31 in the first quartile (Q1), levelling-off to $15,15,17$ thereafter $(p=0.002)$. The proportion of CC0/1 increased from $67 \%$ in Q1 to $77 \%$ Q2 and 74\% Q3/4. Where complete cytoreduction was achieved, 5 and 10-year overall survival was $77 \%$ and $66 \%$. The proportion of patients referred with localised LAMN increased over time reaching $25 \%$ each year since $2010\left(P_{\text {trend }}<0.0001\right)$. Two-thirds of localised LAMN now undergo laparoscopically-assisted risk-reducing CRS.

Conclusion The establishment of a national treatment centre was associated with an initial presentation of patients with advanced disease. The programme has demonstrated a clear trend over time towards earlier referral and adoption of minimal invasive techniques for localised disease.

Word count: 50 (max: 50)

\title{
WHAT DOES THIS PAPER ADD TO THE LITERATURE?
}

Pseudomyxoma peritonei was historically associated with a poor prognosis. Following the establishment of a UK nationally commissioned treatment centre, we observed a trend towards earlier referral, through enhanced referral pathways and improved understanding of disease pathogenesis. We speculate that these changes will result in improved survival and quality of life.

\section{INTRODUCTION}

This article is protected by copyright. All rights reserved. 
Pseudomyxoma peritonei (PMP) is a rare epithelial neoplasm, arising in most cases from a lesion of the appendix known as a low grade appendiceal mucinous neoplasm (LAMN) and characterized by the progressive accumulation of mucinous ascites [1]. The incidence of $\mathrm{PMP}$ in western populations is 1.8 per million population, translating to approximately 120 new cases per year in the UK [2]. Historically, treatment for PMP involved symptomatic relief only, with serial drainage of mucinous ascites or debulking and little prospect of long term survival. Cytoreductive surgery (CRS) combined with heated intraperitoneal chemotherapy (HIPEC) as pioneered by Sugarbaker is now accepted as the standard of care for PMP [3]. Overall 5, 10 and 15 year survival in patients treated by this modality is $75 \%, 63 \%$ and $59 \%$, respectively [4].

Since 2002, services for PMP in the UK have been commissioned centrally via specialist centres in Manchester and Basingstoke. This approach ensures centres receive the case volume required to develop expertise in diagnosis and treatment, and establish robust pathways for patient referral in this relatively rare disease. Commissioning arrangements include monitoring of the service and quality assurance within agreed specifications [5]. Previous studies reported experiences from the individual UK treatment centres [6] [7, 8]; the steep learning curve associated with CRS \& HIPEC [9], and long termsurvival outcomes [4]. However, limitations of existing evidence have been inclusion of heterogeneous series of histopathological types [8] and incomplete or absent disease staging $[4,8]$.

This study aims to evaluate changes in the stage of disease at presentation over a 13-year period in a single centre, assessed prospectively by intra-operative staging with the Peritoneal Cancer Index (PCI), and by the proportion of complete cytoreductions determined by the completeness of cytoreduction score (CC score), as a surrogate quality indicator. We describe how the clinical service has evolved to identify a clinico-pathological early stage disease state [10] and develop novel management strategies to minimise the risk of disease progression [11].

\section{METHODS}

\section{Population and pathways}

Data were extracted from a custom designed prospectively maintained database. All patients referred to the service between January 2002 and December 2015 with a confirmed diagnosis of LAMN or PMP of appendiceal origin were included. Histological diagnostic criteria and classifications were in accordance with the Peritoneal Surface Oncology Group International (PSOGI) consensus classification [12]. Patients with appendiceal goblet cell tumours and with adenocarcinomas were excluded; the latter are reported elsewhere [13].

All patients referred to the service with a suspected diagnosis of LAMN or PMP are discussed by the dedicated peritoneal tumour multidisciplinary team, comprising colorectal and hepatobiliary surgeons, clinical oncologist, radiologist, pathologist, HIPEC practitioners and specialist nurses. All cases undergo in-house pathological and radiological review. Patients with disseminated disease undergo CRS \& HIPEC, or if complete CRS \& HIPEC is deemed unachievable, undergo debulking surgery providing they are fit for major surgical intervention. A proportion of patients with unresectable disease were offered either systemic chemotherapy with Mitomycin C and Capecitabine (MCap) [14] or best supportive care.

This article is protected by copyright. All rights reserved. 
During the evolution of the clinical service, we identified a specific group of patients with a histological diagnosis of LAMN with localised disease limited to the appendix and the immediate peri-appendiceal area i.e. without clinical identifiable intra-abdominal dissemination. We sub-classified these cases based on clinico-pathological features indicative of risk of dissemination [10] as follows: (i) LAMN I, where the lesion was limited to the subserosal appendix with no evidence of appendiceal perforation; and (ii) LAMN II, where the lesion was characterised by appendiceal perforation and/or accompanied by mucin (with or without cells) in the appendix serosa and the peri-appendiceal tissues. The literature demonstrates that LAMN I rarely develops into disseminated disease [15-17] so these patients were offered a programme of active surveillance with interval tumour markers and CT scanning. By contrast, LAMN II is associated with risk of progression to disseminated disease $[15,17]$, with rates in the literature ranging from $16 \%$ in a large, Danish population based study [18], to $23 \%$ in a more recent North American cohort [19]. Patients with LAMN II are counselled and offered risk-reducing CRS \& HIPEC. Some, mainly elderly patients, opt for the LAMN I surveillance pathway. Since 2010, we have offered a minimal access approach for this risk-reducing cytoreductive operation (MACRS).[11]

\section{Surgical Procedure}

CRS involves removal of the appendix and all visible disease by peritonectomy and resection of involved non-essential viscera. In addition, target organs at high chance of involvement and future relapse are resected. Liver surface disease is treated ablatively with high-power electrocautery. HIPEC with mitomycin $\mathrm{C}\left(35 \mathrm{mg} / \mathrm{m}^{3}\right.$ in 3 pulses $)$ is administered after CRS in a semi closed modification of the Coliseum technique [13]. Details of the MACRS procedure are described in an earlier publication [11]

\section{Surveillance}

The surveillance pathway for patients with LAMN I involves 6 monthly review with serum tumour markers (serum CEA, CA19-9, and CA125) plus annual CT scans for five years and a CT scan at year 8 .

\section{Outcomes}

Disease burden was quantified intra-operatively using the Peritoneal Cancer Index (PCI) which scores 13 abdominal sites from 0 (no disease) to 3 (lesions $>5.0 \mathrm{~cm}$ or confluence) giving a score from 0 to a maximum of 39 [20]. Operative disease clearance was quantified by the CC score, assessed intra-operatively at completion of CRS. A score of CC-0 indicates no visible evidence of peritoneal disease; $C C-1$ indicates residual tumour $<2.5 \mathrm{~mm}$ in diameter; CC-2 residual tumour between $2.5 \mathrm{~mm}$ and $2.5 \mathrm{~cm}$ in diameter; and CC-3 residual tumour $>2.5 \mathrm{~cm}$ in diameter or confluence of tumour nodules at any site. CCO/1 is considered complete cytoreduction and CC2/3 is considered debulking [21]. Risk-reducing CRS \& HIPEC is defined as CRS and HIPEC for localised disease (LAMN II and $\mathrm{PCI}<3$ ). Complications were recorded prospectively and classified according to Common Terminology Criteria for Adverse Events (CTCAE) version 3.0 criteria, the agreed classification system to be used for reporting complications relating to CRS \& HIPEC [22].

\section{Statistical analysis}

A complete case analysis approach was used. Twenty-five cases where the PCI score or CC score was not recorded were excluded from analysis. For descriptive purposes, we divided our cohort into four approximate quartiles based on the number of referred cases, as used in equivalent papers [8]. These quartiles corresponded to the four time cohorts (TC) - TC1:

This article is protected by copyright. All rights reserved. 
2002-07; TC2: 2008-10, TC3: 2011-13; and TC4: 2014-15. s.

We tracked the geographical residency of patients using postal codes using Tableau Software (Seattle, USA), and visually examined for changes in geographic referral variations over the four TCs.

$\mathrm{PCl}$ data were modelled with time using spline regression repeated iteratively for cutoff points at each year to determine the optimal pivot, as described elsewhere [23]. Confidence intervals for proportions were calculated using the Wilson score method without continuity correction[24]. Cochran-Armitage test[25] was used for trends in proportions. Chi square was used for differences in proportions.

Overall survival probabilities s (any cause of death) were estimated from time of operation using Kaplan-Meier life tables. Comparisons were performed using log-rank tests. All analyses were carried out using Microsoft ${ }^{\circledR}$ Excel (Microsoft Corporation, Redmond, Washington, USA) XLStat (Addinsoft, Paris, France) and Stata ${ }^{\circledR} 142$ software (College Station, TX).

\section{RESULTS}

\section{Referral Patterns}

Over the 13-year period, 1047 patients with suspected PMP were referred to the Colorectal and Peritoneal Oncology Centre (CPOC) (Figure 1). The following were excluded: 205 with non-PMP pathologies and 25 with missing $\mathrm{PCl}$ or $\mathrm{CC}$ scores. The principle analysis was of the remaining 817 patients with confirmed PMP either as disseminated (N:612) or localised disease (N: 205).

Patients were referred mainly from the North and Midlands of England, Scotland, Northern Ireland and North Wales. Over the four time cohorts, the geographical distribution of referrals was similar (Figure 2).

The total number of referrals per year increased over the 13-year period. In particular, patients referred with localised disease significantly increased over time $\left(P_{\text {trend }}\right.$ $<0.0001$ ), and constituted over $25 \%$ of referrals per year since 2010 , and $32 \%$ of referrals in 2015 alone (Figure 3).

\section{Management pathways}

Of the 612 patients with disseminated disease, 330 (40\%) underwent CRS \& HIPEC. For the remaining 282 patients, management was: palliative drainage $(\mathrm{N}: 16)$; palliation $(\mathrm{N}$ : 128$)$; systemic MCap chemotherapy ( $\mathrm{N}: 40)$ and active monitoring ( $N: 55)$ (Figure 1). Forty three patients either declined treatment/follow-up, were transferred to an alternative centre for treatment, were lost to follow-up or died before treatment was commenced.

Of the 205 patients (23\%) with localised disease (LAMN I or II), 129 (63\%) were managed with active surveillance. 76 (37\%) patients with LAMN II underwent risk-reducing CRS \& HIPEC, and since 2010 the majority of these were undertaken via a minimally invasive approach (Table 1).

This article is protected by copyright. All rights reserved. 


\section{Disease Burden}

$\mathrm{PCl}$ scores are plotted against year of operation for cytoreduction (CCO/CC1) and debulking (CC2/CC3) procedures (Figure 4). For the first quartile of cases, disease burden was high (mean PCI: 31), and levelled-off, thereafter $(15,15,17 ; p=0.002)$. There was an absence of low $(<20) \mathrm{PCl}$ values in the early study period. We tested statistically for a pivot in the data using spline models. The optimal pivot was at $2007(p=0.002)$. The spline regression for yearly mean $\mathrm{PCl}$ scores for years 2002 to 2007 declined significantly $(P<0.001)$, but the yearly mean score levelled off thereafter $(p=0.48)$.

\section{Surgical clearance of disease}

Of patients undergoing major laparotomy for disseminated disease, the proportion undergoing complete cytoreduction (CC0/1) was $66.7 \%(56 / 84)$ in the first time-cohort. This increased to $77.1 \%$ (54/70) in TC2 although this increase was not statistically significant $(\mathrm{P}=0.14)$. Proportions of complete cytoreduction in TC3 and TC4 were $73.6 \%(67 / 91)$ and $74.1 \%$ (63/85), respectively (Figure 5). CC0 cytoreduction was achieved in all patients undergoing risk reducing CRS and HIPEC.

\section{Complications}

Rates of NCI CTCAE grade 3 to 5 surgical complications for all CRS \& HIPEC procedures by time cohort were $4.3 \% ; 9.5 \%, 14.5 \%$ and $12.5 \%$. There was one 30 -day mortality.

\section{Survival}

Five- and 10-year overall survival for patients undergoing CRS \& HIPEC for disseminated disease (excluding risk reducing procedures) was $77 \%$ and $66 \%$, respectively. Incomplete cytoreduction (CC2/3) was associated with significantly worse survival compared with complete cytoreduction (CC0/1) $(P<0.0001)$ (Figure 6).

\section{Discussion}

\section{Main findings}

This paper describes the evolution of a nationally commissioned specialist service over 13 years. The number of referrals received has increased over time. This increase is likely to be driven by the establishment of robust referral pathways resulting in increased awareness of services amongst the referring community. High volumes of disease were seen in the early years of the service, illustrated by the high mean PCI score in TC1 (31), but mean PCI score stabilised at a lower level over subsequent years. This most likely represents an initial phase, where patients with established advanced disease accessed the service following increased awareness of the healthcare provider. The number of patients referred with localised disease (LAMN) has increased, representing a progressively greater proportion of the total referrals year on year. This increase may be explained by an increasing awareness of the role of appendiceal precursor lesions in the development of PMP and better understanding of specialist services (for example, through national meetings and MDT workshops). We have described new risk stratified management pathways for patients with localised disease, which balance the potential morbidity of intervention against the risk of developing disseminated disease.

\section{Context of other literature}

The classification of PMP and its appendiceal precursor has been the subject of extensive debate in the literature, prompting the publication of an international consensus for

This article is protected by copyright. All rights reserved. 
classification and pathologic reporting in 2016 [12]. The consensus document clearly differentiates between appendiceal mucinous neoplasms and appendiceal mucinous adenocarcinoma. The latter term is reserved for mucinous tumours with infiltrative invasion, associated with a more aggressive natural history, metastasizing systemically in up to $20 \%$ of cases [18]. To our knowledge, this is the only study to date to describe a homogenous, pathologically consistent cohort of patients with PMP originating from appendiceal mucinous neoplasia excluding appendiceal adenocarcinoma.

Rates of complete cytoreduction for disseminated disease in our cohort have remained around $74 \%$ since 2007 , reflecting the relatively constant yearly mean PCl score observed after the first quartile. Chua et al. (JCO 2010) reported a pooled analysis from 16 units across 3 continents and quotes an overall CC0/1 rate of $83 \%$ [4]. It is important to note that this analysis pooled all data without simultaneously accounting for between-centre variance and arguably our proportion of $74 \%$ would fall within this range. Further, in our series, risk reducing procedures have been considered separately. And when these are included, the $\mathrm{CC} 0 / 1$ rate is more comparable at $79 \%$. The importance of achieving complete cytoreduction is underlined by the significant difference in survival between those undergoing $\mathrm{CCO} / 1$ resection and those undergoing debulking (CC2/3). Notably, there are no survivors beyond 9 years in the latter group. Combined overall survival at 5 and 10 years in our cohort $77 \%$ and $66 \%$, respectively) is comparable to other published series, which range from $51-82 \%$ at 5 years $[4,6,26,27]$ and $32-76 \%$ at 10 years $[4,8,26]$.

\section{Strengths and limitations}

This study has several strengths. Firstly, data on treatments, complications, $\mathrm{PCl}$ and surgical and oncological outcomes were collected prospectively. Secondly, we present a large, mature andpathologically homogenous data set, with a minimum follow-up period of three years and minimal missing data (3\%) across all fields. The only other study to report $\mathrm{PCI}$ score in patients undergoing CRS \& HIPEC for PMP [4] cites the PCI score as missing in $35 \%$ of cases. Thirdly, we included the management outcomes of all patients referred with PMP, including those not undergoing surgery Other studies have either excluded patients not undergoing surgery $[4,26-28]$ or reported the proportion of referred patients not undergoing CRS \& HIPEC, but included a heterogenous case mix of peritoneal surface malignancies including mesothelioma and colorectal peritoneal metastases and provided no further detail on the management outcomes of this group [8].

The limitations of this study relate to the difficulties associated with describing longterm outcomes beyond survival. We describe overall survival but do not report disease-free interval or progression largely because a clear and consistent definition of progression in the context of PMP has not yet been agreed. One recent large multicentre cohort reported progression-free survival (PFS) [4] in the context of disseminated disease, but did not provide an accompanying definition of PFS. An earlier single centre cohort included rise in tumour markers in its definition of progression [29]. A reproducible definition will need to specify disease criteria (new lesions and quantifying change in existing lesions) and assessment modality [13]. Such outcomes will be particularly important in the long-term follow-up of patients having risk reducing procedures or under active surveillance for localised disease and therefore agreeing consistent and reproducible outcome measures is a key research priority.

\section{Future research}

This article is protected by copyright. All rights reserved. 
Earlier referral of patients with localised disease has allowed an increasing number of patients to be managed either by risk reducing surgery or active surveillance. The long-term impact of these management pathways on survival and disease progression is being monitored over time.

High 5- and 10-year survival rates following complete cytoreduction for disseminated disease is clearly a success, but survivors are now living with morbidities following CRS and HIPEC.. We have recently analysed and reported QoL in patients undergoing CRS and HIPEC for PMP showing impaired cognitive function at 1 year post treatment [30]. We are currently undertaking qualitative work to understand the priorities of patients in this population.

In conclusion, central commissioning of specialist services has facilitated the development of robust referral pathways leading to high volume specialist centres with quality assured outcomes. These features of centralisation are associated with favourable outcomes in patients with PMP [9] .Our data illustrate the change over time in disease stage at referral, demonstrating a clear trend towards referral at an earlier stage of disease and describe new risk stratified management pathways. We speculate that in the long-term these service changes will result in improved survival, reduced treatment-related morbidity, and improved health-related quality of life, and these are areas for ongoing research.

\section{REFERENCES}

1. Renehan A, Stern P, O'Dwyer S. Pseudomyxoma Peritonei. In: Schwab M, editor.: Springer Berlin Heidelberg; 2012. p. 3113-6.

2. van den Heuvel MG, Lemmens VE, Verhoeven $\mathrm{RH}$, de Hingh IH. The incidence of mucinous appendiceal malignancies: a population-based study. International journal of colorectal disease. 2013;28(9):1307-10.

3. Sugarbaker PH. New standard of care for appendiceal epithelial neoplasms and pseudomyxoma peritonei syndrome? Lancet Oncology. 2006;7(1):69-76.

4. Chua TC, Moran BJ, Sugarbaker PH, Levine Ea, Glehen O, Gilly FN, et al. Early- and long-term outcome data of patients with pseudomyxoma peritonei from appendiceal origin treated by a strategy of cytoreductive surgery and hyperthermic intraperitoneal chemotherapy. Journal of Clinical Oncology. 2012;30(20):2449-56.

5. Comissioning Board N. Pseudomyxoma peritonei service (Adult) Service Specification A08/S(HSS)/b 2013 [Available from: https://www.england.nhs.uk/wpcontent/uploads/2013/06/a08-pseud-peri-ad.pdf.

6. Rout S, Renehan aG, Parkinson MF, Saunders MP, Fulford PE, Wilson MS, et al. Treatments and outcomes of peritoneal surface tumors through a centralized national service (United Kingdom). Diseases of the Colon and Rectum. 2009;52(10):1705-14.

7. Ansari N, Chandrakumaran K, Dayal S, Mohamed F, Cecil TD, Moran BJ.

Cytoreductive surgery and hyperthermic intraperitoneal chemotherapy in 1000 patients with perforated appendiceal epithelial tumours. Eur J Surg Oncol. 2016;42(7):1035-41.

8. Moran B, Cecil T, Chandrakumaran K, Arnold S, Mohamed F, Venkatasubramaniam

A. The results of cytoreductive surgery and hyperthermic intraperitoneal chemotherapy in 1200 patients with peritoneal malignancy. Colorectal Disease. 2015;17(9):772-8.

9. Kusamura S, Moran BJ, Sugarbaker PH, Levine EA, Elias D, Baratti D, et al. Multicentre study of the learning curve and surgical performance of cytoreductive surgery with intraperitoneal chemotherapy for pseudomyxoma peritonei. British Journal of Surgery. 2014;101(13):1758-65.

10. McDonald JR, O'Dwyer ST, Rout S, Chakrabarty B, Sikand K, Fulford PE, et al. Classification of and cytoreductive surgery for low-grade appendiceal mucinous neoplasms.

This article is protected by copyright. All rights reserved. 
British Journal of Surgery. 2012;99(7):987-92.

11. Fish R, Selvasekar C, Crichton P, Wilson M, Fulford P, Renehan A, et al. Riskreducing laparoscopic cytoreductive surgery and hyperthermic intraperitoneal chemotherapy for low-grade appendiceal mucinous neoplasm : early outcomes and technique. 2013. 12. Carr NJ, Cecil TD, Mohamed F, Sobin LH, Sugarbaker PH, González-Moreno S, et al. A Consensus for Classification and Pathologic Reporting of Pseudomyxoma Peritonei and Associated Appendiceal Neoplasia: The Results of the Peritoneal Surface Oncology Group International (PSOGI) Modified Delphi Process. The American Journal of Surgical Pathology. 2016;40(1):14-26.

13. Aziz O, Jaradat I, Chakrabarty B, Selvasekar CR, Fulford PE, Saunders MP, et al. Predicting survival after cytoreductive surgery and hyperthermic intraperitoneal chemotherapy (HIPEC) for adenocarcinoma of the appendix [accepted]. Diseases of Colon and Rectum.

14. Farquharson AL, Pranesh N, Witham G, Swindell R, Taylor MB, Renehan AG, et al. A phase II study evaluating the use of concurrent mitomycin $C$ and capecitabine in patients with advanced unresectable pseudomyxoma peritonei. British Journal of Cancer. 2008;99(4):591-6.

15. Yantiss RK, Shia J, Klimstra DS, Hahn HP, Odze RD, Misdraji J. Prognostic significance of localized extra-appendiceal mucin deposition in appendiceal mucinous neoplasms. Am J Surg Pathol. 2009;33(2):248-55.

16. Misdraji J, Yantiss RK, Graeme-Cook FM, Balis UJ, Young RH. Appendiceal mucinous neoplasms: a clinicopathologic analysis of 107 cases. Am J Surg Pathol. 2003;27(8):1089-103.

17. Pai RK, Beck AH, Norton JA, Longacre TA. Appendiceal mucinous neoplasms: clinicopathologic study of 116 cases with analysis of factors predicting recurrence. Am J Surg Pathol. 2009;33(10):1425-39.

18. Smeenk RM, van Velthuysen MLF, Verwaal VJ, Zoetmulder FAN. Appendiceal neoplasms and pseudomyxoma peritonei: A population based study. European Journal of Surgical Oncology. 2008;34(2):196-201.

19. Foster JM, Sleightholm RL, Wahlmeier S, Loggie B, Sharma P, Patel A. Early identification of DPAM in at-risk low-grade appendiceal mucinous neoplasm patients: a new approach to surveillance for peritoneal metastasis. World Journal of Surgical Oncology. 2016;14(1):243.

20. Sugarbaker PH. Management of peritoneal-surface malignancy: the surgeon's role. Langenbeck's archives of surgery / Deutsche Gesellschaft fur Chirurgie. 1999;384(6):576-

87.

21. Sugarbaker $\mathrm{PH}$, Chang D. Results of Treatment of 385 Patients With Peritoneal

Surface Spread of Appendiceal Malignancy. Annals of Surgical Oncology. 1999;6(8):727-31.

22. Younan R, Kusamura S, Baratti D, Cloutier AS, Deraco M. Morbidity, toxicity, and mortality classification systems in the local regional treatment of peritoneal surface malignancy. Journal of surgical oncology. 2008;98(4):253-7.

23. New JP, Aung T, Baker PG, Yongsheng G, Pylypczuk R, Houghton J, et al. The high prevalence of unrecognized anaemia in patients with diabetes and chronic kidney disease: a population-based study. Diabetic medicine : a journal of the British Diabetic Association. 2008;25(5):564-9.

24. Newcombe Robert G. Interval estimation for the difference between independent proportions: comparison of eleven methods. Statistics in Medicine. 1998;17(8):873-90.

25. Armitage P. Tests for Linear Trends in Proportions and Frequencies. Biometrics. 1955;11(3):375-86.

26. Levine EA, Stewart JH, Shen P, Russell GB, Loggie BL, Votanopoulos KI. Cytoreductive Surgery and Hyperthermic Intraperitoneal Chemotherapy for Peritoneal Surface Malignancy: Experience with 1,000 Patients. Journal of the American College of Surgeons. 2014;218(4):573-85.

27. Glehen O, Gilly FN, Boutitie F, Bereder JM, Quenet F, Sideris L, et al. Toward curative treatment of peritoneal carcinomatosis from nonovarian origin by cytoreductive

This article is protected by copyright. All rights reserved. 
surgery combined with perioperative intraperitoneal chemotherapy: a multi-institutional study of 1,290 patients. Cancer. 2010;116(24):5608-18.

28. Lord AC, Shihab O, Chandrakumaran K, Mohamed F, Cecil TD, Moran BJ.

Recurrence and outcome after complete tumour removal and hyperthermic intraperitoneal chemotherapy in 512 patients with pseudomyxoma peritonei from perforated appendiceal mucinous tumours. European Journal of Surgical Oncology. 2015;41(3):396-9.

29. Smeenk RM, Verwaal VJ, Antonini N, Zoetmulder FA. Progression of pseudomyxoma peritonei after combined modality treatment: management and outcome. Ann Surg Oncol. 2007;14(2):493-9.

30. Stearns AT, Malcomson L, Punnett G, Abudeeb H, Aziz O, Selvasekar CR, et al. Long-term Quality of Life After Cytoreductive Surgery and Heated Intraperitoneal

Chemotherapy for Pseudomyxoma Peritonei: A Prospective Longitudinal Study. Annals of Surgical Oncology. 2018.

\section{Table 1 Summary characteristics by time cohort}

\begin{tabular}{lcccc} 
& $\begin{array}{c}\text { TC1 } \\
(\mathbf{n = 2 0 0 )}\end{array}$ & $\begin{array}{c}\text { TC2 } \\
(\mathbf{n}=\mathbf{1 8 7})\end{array}$ & $\begin{array}{c}\text { TC3 } \\
(\mathbf{n}=\mathbf{2 1 6})\end{array}$ & $\begin{array}{c}\text { TC4 } \\
(\mathbf{n}=\mathbf{2 1 4})\end{array}$ \\
\hline Time period & $2002-07$ & $2008-10$ & $2011-13$ & $2014-15$ \\
Male: Female & $68: 132$ & $72: 115$ & $69: 147$ & $61: 153$ \\
Median Age (range) & $56(18-86)$ & $56(22-94)$ & $59(22-85)$ & $61(21-90)$ \\
Mean PCl score (SD) & $31(28)$ & $15(15)$ & $15(10)$ & $17(11)$ \\
Disseminated disease (PMP) & 185 & 138 & 146 & 143 \\
$\quad$ Major laparotomy & $84(45)$ & $70(51)$ & $91(62)$ & $85(59)$ \\
$\quad$ (major debulking to CRS) (\%) & & & & 71 \\
Localised Disease (LAMN I/II) & 15 & 49 & 70 & 52 \\
$\quad$ Watch \& wait & 8 & 25 & 44 & 19 \\
$\quad$ Risk Reducing CRS \& HIPEC & 7 & 24 & 26 & $13(68)$ \\
$\quad$ MACRS (\%) & 0 & $2(8)$ & $19(73)$ & \\
\hline
\end{tabular}

TC: time cohort; SD: standard deviation.

CC: completeness of cytoreduction; CRS: cytoreductive surgery; HIPEC: heated intraperitoneal chemotherapy; LAMN: low-grade appendiceal mucinous neoplasm; MACRS: minimally invasive cytoreductive surgery; $\mathrm{PCl}$ : peritoneal cancer index; PMP: pseudomyxoma peritonei.

This article is protected by copyright. All rights reserved. 


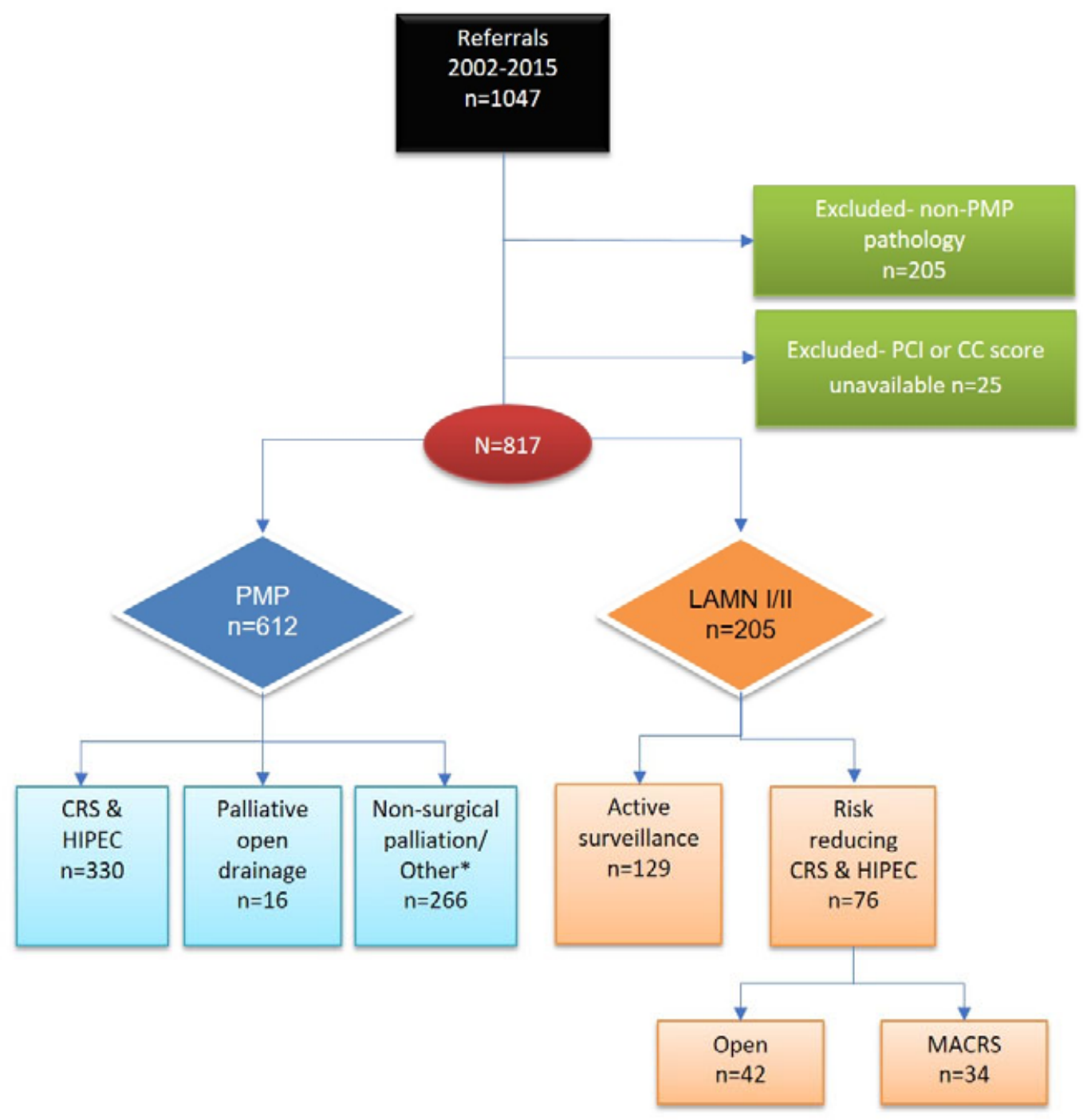

Figure 1 Management pathways. PMP: pseudomyxoma peritonei; LAMN: low-grade appendiceal mucinous neoplasm (combined clinical and pathological diagnosis with disease limited to immediate peri-appendiceal tissues [10]); CRS: cytoreductive surgery; HIPEC: heated intra-peritoneal chemotherapy; $\mathrm{PCl}$ : peritoneal cancer index; $\mathrm{CC}$ : completeness of cytoreduction. MACRS: Minimally invasive cytoreductive surgery.

*Includes palliation (128), systemic chemotherapy (40); active monitoring (55) and other ${ }^{\dagger}(43)$. IIncludes: Lost to f/u; declined treatment or $F / U$; transferred care to alternative centre; died before treatment commenced;

This article is protected by copyright. All rights reserved. 

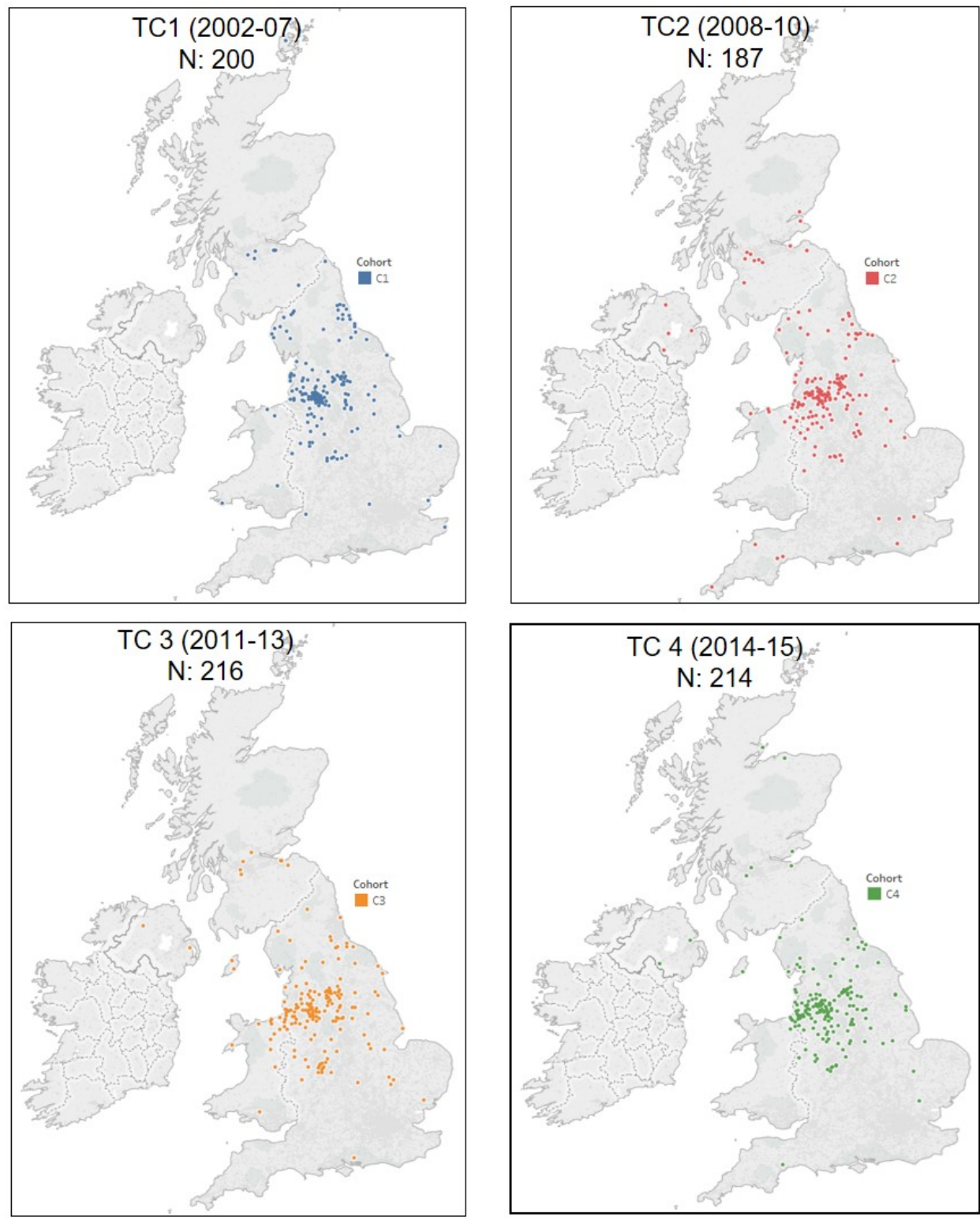

Figure 2 Geographical origin of referrals (derived from postcodes) by four time cohorts

This article is protected by copyright. All rights reserved. 


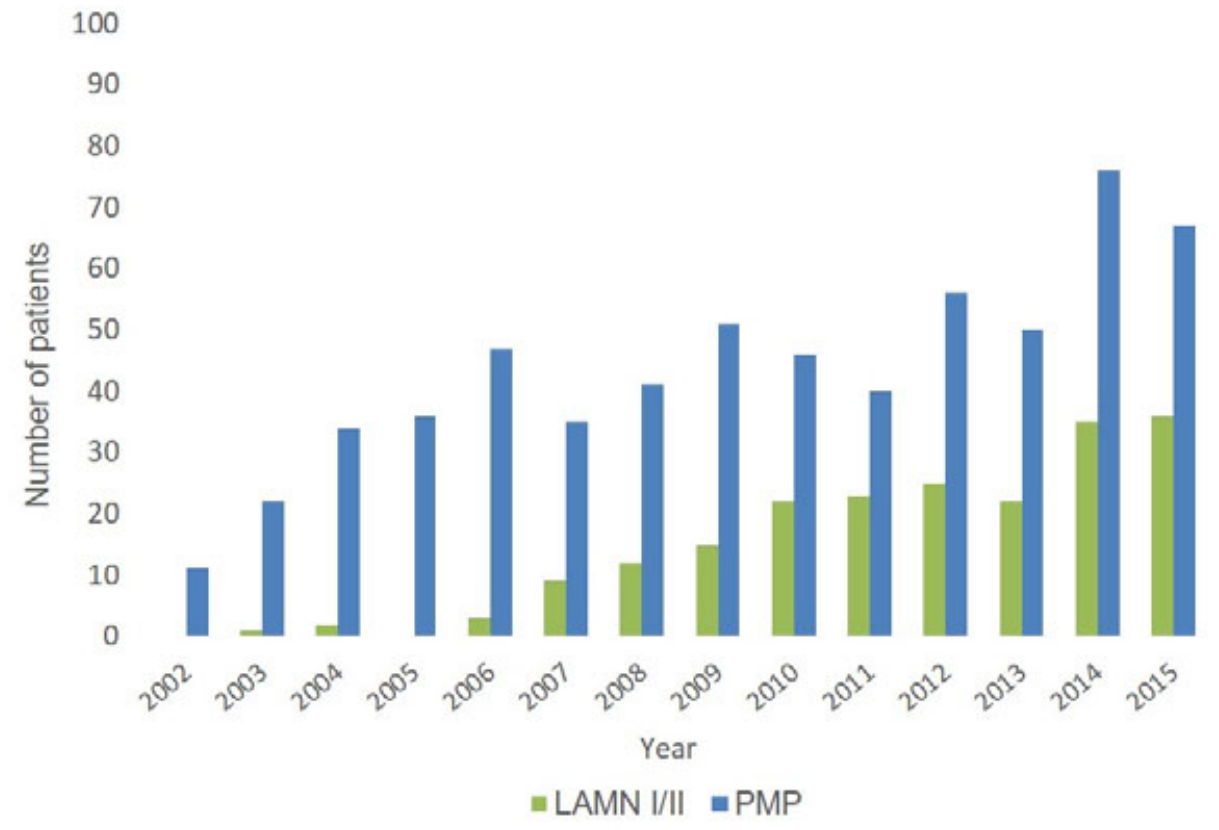

Figure 3 Number of referrals per year with localised disease (LAMN I/II) or disseminated disease (PMP). PMP: pseudomyxoma peritonei; LAMN: low-grade appendiceal mucinous neoplasm (combined clinical and pathological diagnosis with disease limited to immediate periappendiceal tissues).

This article is protected by copyright. All rights reserved. 


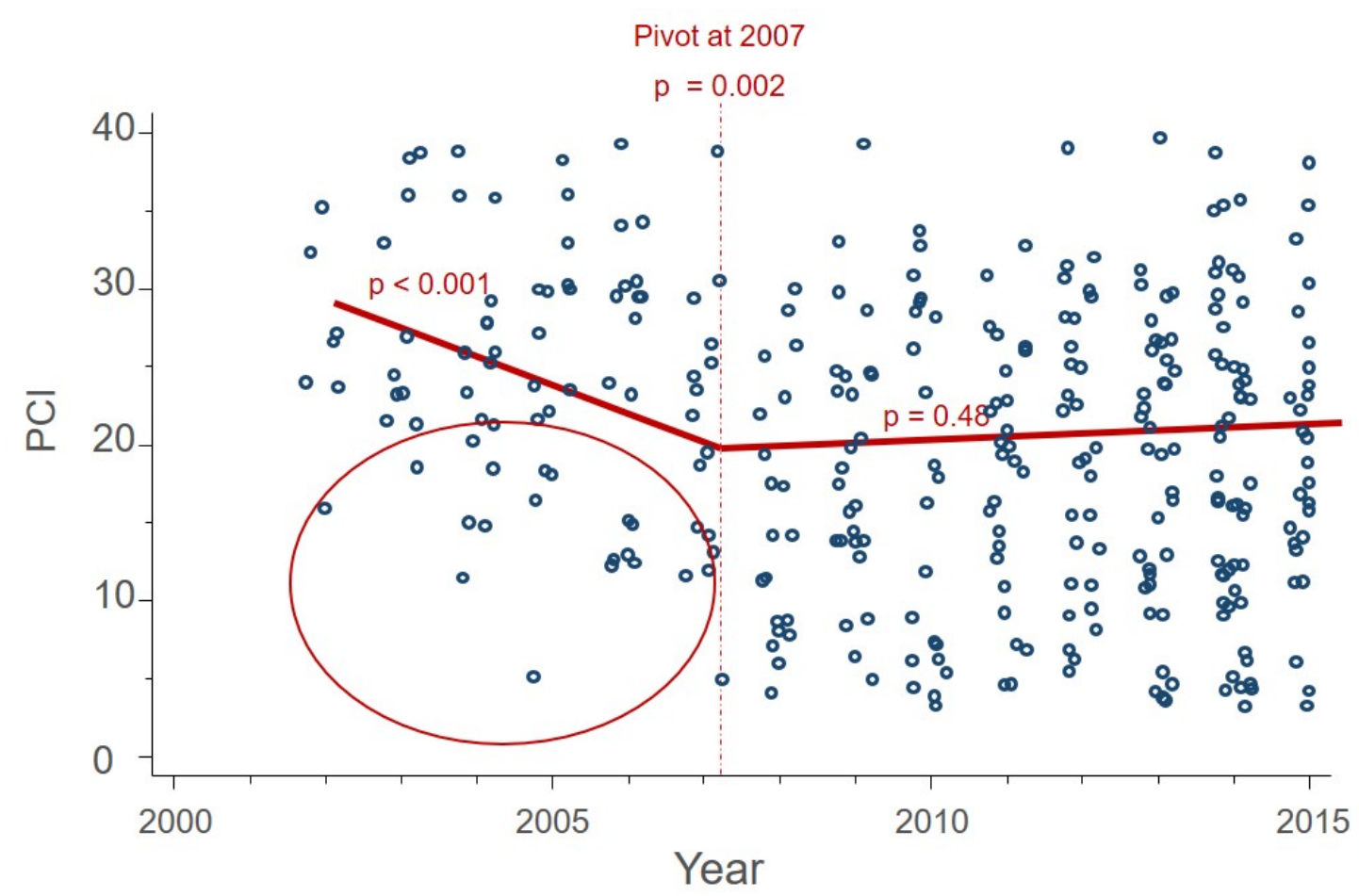

Figure $4 \mathrm{PCl}$ scores by year of operation for debulking (CC2/CC3) and cytoreduction (CC0/CC1) procedures. Red circle demonstrates absence of low $\mathrm{PCl}$ values in the early study period. $\mathrm{PCl}$ : Peritoneal cancer index

This article is protected by copyright. All rights reserved. 


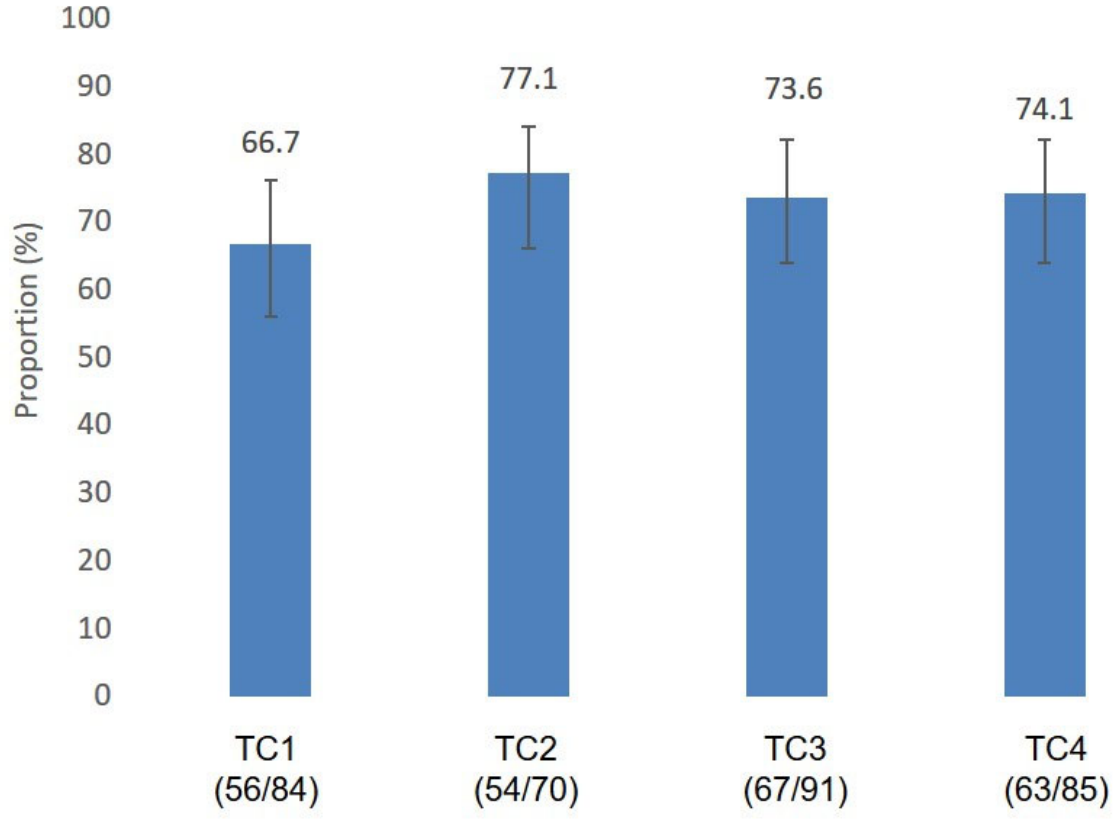

Figure 5 Proportion of patients undergoing surgery for advanced disease in whom complete cytoreduction is achieved. Error calculated using Wilson score method. $\mathrm{TC}=$ time cohort.

This article is protected by copyright. All rights reserved. 


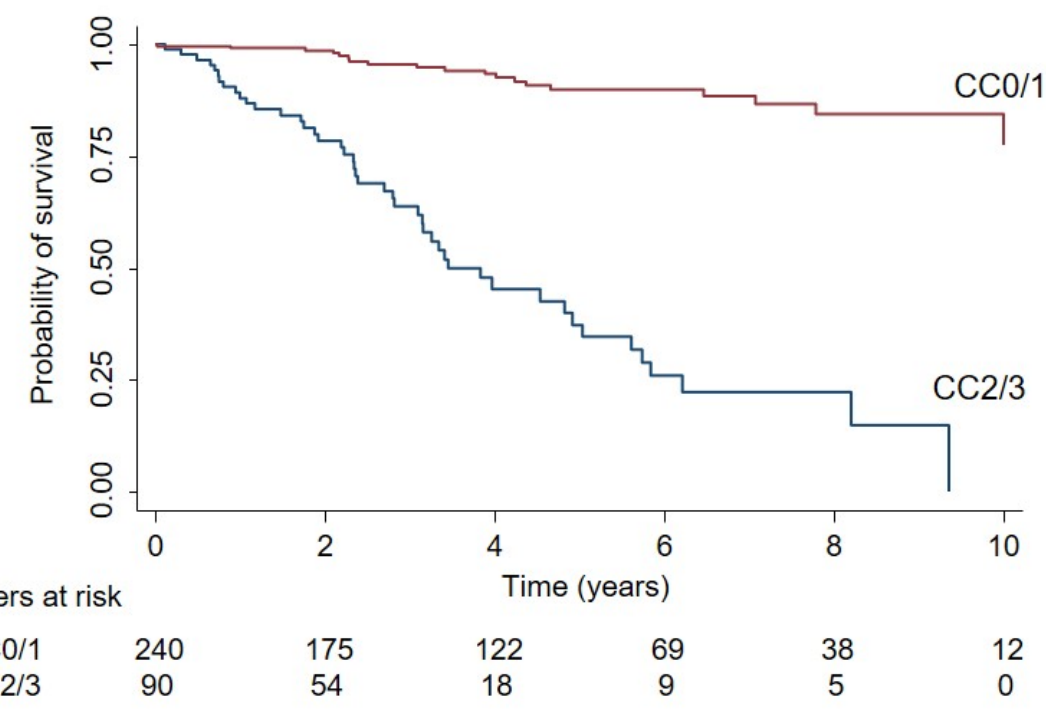

Figure 6 Kaplan-Meier overall survival estimates for 330 patients with disseminated PMP undergoing cytoreductive surgery $(\mathrm{CC} 0 / 1)$ and major debulking surgery $(\mathrm{CC} 2 / 3)$.

This article is protected by copyright. All rights reserved. 